\title{
Clinical Reasoning: A patient with multiple cranial nerve palsies and areflexic paraparesis
}

Ravindra Kumar Garg, DM, Imran Rizvi, DM, Hardeep Singh Malhotra, DM, Manan Mayur Mehta, MD, Mili Jain, MD, Madhu Mati Goel, MD, Ravi Uniyal, DM, and Neeraj Kumar, DM

Neurology ${ }^{\circledR}$ 2018;91:e392-e395. doi:10.1212/WNL.0000000000005865

\section{Section 1}

A 62-year-old hypertensive man presented with 1.5-month history of bilateral facial nerve palsy evolving over 5 days, followed by double vision and restriction of eye movements for 1 month. He had progressive deterioration of vision of 20 days duration. His vital measures, except blood pressure $(174 / 104 \mathrm{~mm} \mathrm{Hg})$, were normal. The patient was conscious, oriented, and obeyed commands and instructions. His vision was limited to appreciation of hand movements. Ophthalmoscopy revealed bilateral disk swelling with grade II hypertensive retinopathy. Pupils were dilated with a sluggish reaction to light. Cranial nerve examination further revealed bilateral third, fourth, sixth, and seventh cranial nerve palsies. Trigeminal nerve (V1-V3) sensations were intact. Hearing was normal. There was no tongue or palate weakness/ asymmetry. Tongue bulk was normal. Sternocleidomastoid and trapezius were normal. Power in the upper limbs was normal. In the lower limbs, power in all groups of muscles was grade $3 / 5$ (Medical Research Council grade). There was generalized areflexia. Planters were flexor. Sensory examination was normal. There was nuchal rigidity with a positive Kerning sign. Other systemic and general examinations were unremarkable.

\section{Question for consideration:}

1. What is the likely anatomical localization?

The patient had bilateral optic nerve and seventh nerve involvement, with bilateral external ophthalmoplegia, but lacking any long tract sign. Visual disturbance with external ophthalmoplegia involving multiple cranial nerves helped us in localizing the site of involvement to a true orbital apex syndrome, a modified superior orbital fissure syndrome, or an extending cavernous sinus syndrome. Involvement of vision is considered an important differentiating feature dissecting a true orbital apex syndrome from superior orbital fissure and cavernous sinus afflictions. The trigeminal nerve (V1 and V2 divisions) that traverses the lateral wall of the cavernous sinus was normal in our case. Facial nerve involvement, typically not found in either cavernous or orbital apex syndromes, suggests extensive cranial meningeal involvement. Areflexic paraparesis suggests polyradiculopathy due to spinal meningeal involvement. Multiple cranial nerve palsies and the presence of meningeal signs, along with lower motor neuron pattern weakness in limbs, suggest diffuse leptomeningeal involvement.
Correspondence

Ravindra Kumar Garg garg50@yahoo.com

GO TO SECTION 2 


\section{Section 2}

The patient was an elderly, apparently immunocompetent, man having presented with a subacute disease course. Multiple cranial nerve involvement with polyradiculopathy suggested an extensive cranial and spinal meningeal involvement.

\section{Question for consideration:}

1. What are the differential diagnoses in this patient?

Cranial nerves pass through many bony foramina in the base of the skull and traverse through basal meninges to various parts of the head and the neck. Cranial nerves, throughout their course, are vulnerable to various localized or systemic insults. Similarly, the spinal nerves, after emerging from the spinal cord, are vulnerable to various localized or systemic disorders. A large number of diseases, like malignancy, infections, vasculitides, and connective tissue disorders, can simultaneously affect multiple cranial and spinal nerve roots. We considered tuberculous meningitis, sarcoidosis, connective tissue disorders, vasculitides, fungal infections, and leptomeningeal carcinomatosis in our differential diagnoses. Miller-Fisher variant of Guillain-Barré syndrome is a close differential diagnosis in a patient with ophthalmoplegia and areflexia, but the presence of other cranial neuropathies made it unnecessary to consider further workup.

Tuberculous meningitis is a common infective condition that can cause simultaneous multiple cranial nerve palsies and spinal arachnoiditis. Neuroimaging demonstrates diffuse, segmental, or nodular thickening, with enhancement of the meninges. Signal changes in spinal cord parenchyma and intrinsic cord tuberculoma are also frequently noted. ${ }^{1}$

Sarcoidosis is a systemic granulomatous condition of unknown etiology that has been shown to affect nearly every organ system of the body. The common neurologic manifestations of sarcoidosis are cranial nerve palsies, headache, and seizures. Facial nerve, unilateral or more characteristically bilateral, is the most frequently involved cranial nerve. Sarcoidosis can affect spinal cord too. Typical spinal cord neuroimaging changes include leptomeningeal enhancement, an intramedullary mass, nerve root clumping, and enhanced nerve root sheaths. ${ }^{2}$ Disseminated involvement of multiple cranial nerve and spinal nerve roots can be seen in vasculitis, as well. Wegener granulomatosis produces cranial nerve palsies and involves the optic nerve. ${ }^{3}$ Polyradicular meningeal involvement can be seen in vasculitis because of arteritic or embolic occlusion of vessels supplying the nerve roots. Fungal infections like mucormycosis can affect multiple cranial nerves but the involvement of spinal nerve roots is less common.

Invasion of the cranial and spinal leptomeninges by a systemic cancer can cause multiple cranial nerve palsies along with an extensive radiculopathy, with or without the involvement of the spinal cord. Metastatic seeding of the cancer cells in leptomeninges is known as carcinomatous meningitis if the primary malignancy is a solid tumor. However, in cases with a lymphoma, it is known as lymphomatous meningitis or leukemic meningitis if the primary disorder is a leukemia. Neuroimaging shows leptomeningeal enhancement, subarachnoidal nodular filling defects, clumping of roots of the cauda equina, and thickening and enhancement of nerve roots. Breast cancer, lung cancer, and melanoma are the 3 most common solid malignancies known to cause carcinomatous meningitis. Infrequently, carcinomatous meningitis may be the presenting manifestation of systemic malignancies. Leukemic and lymphomatous meningitis tend to have a higher frequency of cranial nerve involvement. ${ }^{4}$ In a series, 979 patients with simultaneous or serial involvement of 2 or more different cranial nerves were evaluated; almost one-third of patients had a tumor as the reason for multiple cranial neuropathies. Lymphomas and leukemias were diagnosed in $10 \%$ and $3 \%$ of cases, respectively. ${ }^{5}$

GO TO SECTION 3 


\section{Section 3}

Although the incidence of getting diagnosed with a malignancy increases with age, infections and certain immunologic disorders also tend to occur with an increased frequency in elderly patients. Thus, a systematic approach towards the comprehensive evaluation of such a state is required. The investigations, at the same time, need to be customized to avoid unnecessary evaluation and procedures.

\section{Question for consideration:}

1. Which diagnostic testing is required?

\section{Imaging}

MRI of the brain showed bilateral contrast enhancement in the region of cavernous sinus, extending to the orbital apex. A contrast-enhanced spinal MRI did not reveal any leptomeningeal enhancement. Chest X-ray, ultrasound of the abdomen and pelvis, and contrast-enhanced CT of thorax and abdomen were unremarkable (figure, A and B).

\section{Lumbar puncture}

The patient's CSF opening pressure was elevated $(350 \mathrm{~mm}$ $\mathrm{H}_{2} \mathrm{O}$ ). CSF examination showed protein $300 \mathrm{mg} \%$ and glucose $41 \mathrm{mg} \%$ with a corresponding blood glucose of $117 \mathrm{mg} \%$. The cell count in CSF was 19,080 (polymorphs 15\%, lymphocytes $10 \%$, and atypical cells $75 \%$ ) (figure, C). PCR for tuberculosis and cryptococcal latex agglutination test was negative.

\section{Blood tests}

Laboratory evaluation revealed hemoglobin of $14.4 \mathrm{~g} / \mathrm{dL}$, total leukocyte count of 200,000 cells $/ \mathrm{mm}^{3}$ ( $\mathrm{n}=71 \%, \mathrm{~L}=$

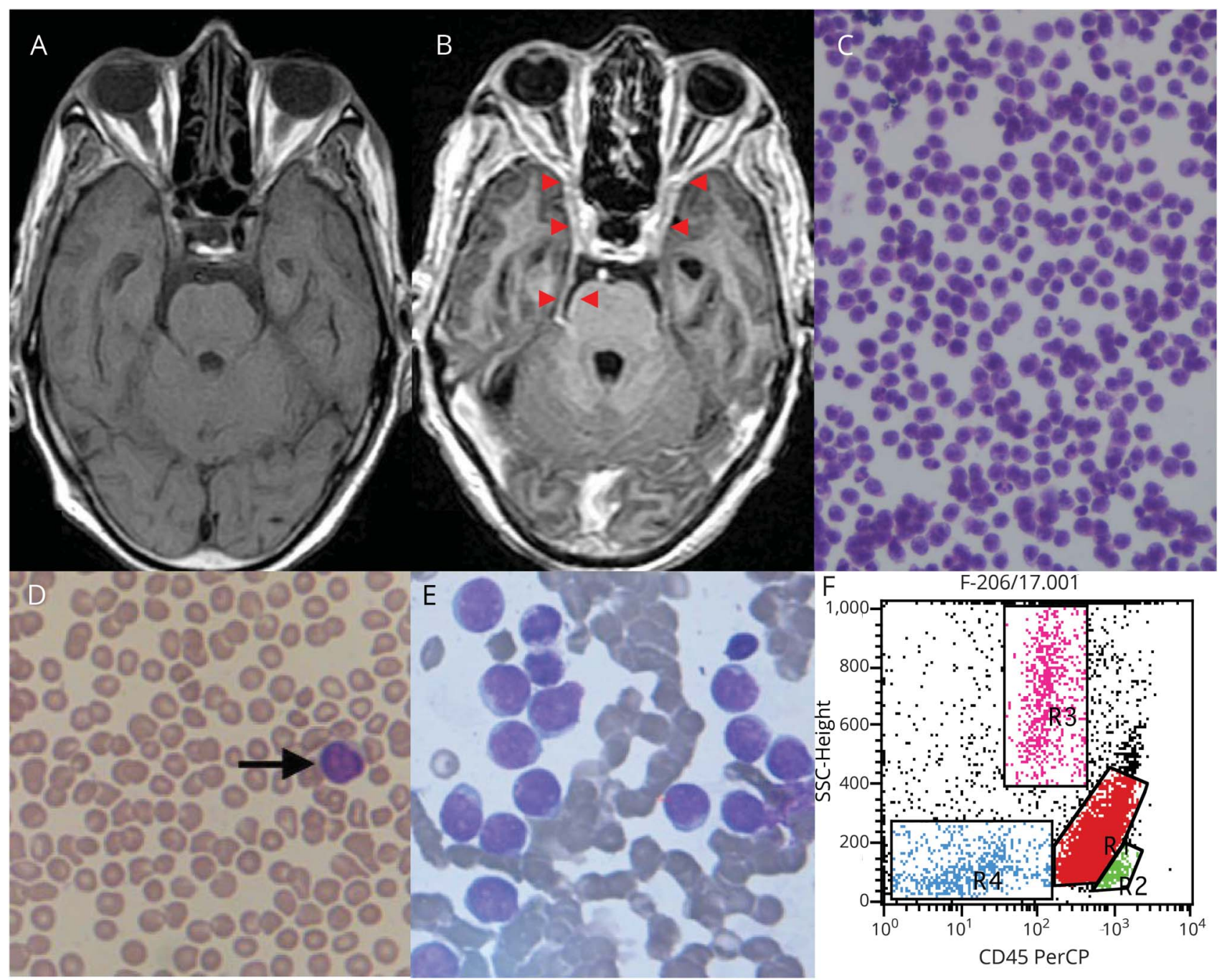

CSF shows leukemic cells. Bone marrow examination confirmed acute lymphoblastic leukemia. MRI of the brain depicts gadolinium contrast enhancement (arrowheads) in the cavernous sinuses, orbital apices, and the associated meningeal and brainstem interfaces, on axial spoiled gradient recalled image (B) as compared to corresponding axial T1-weighted image (A). CSF cytosmear (C) depicts a monotonous population of atypical lymphoid cells. Peripheral blood smear (D), Leishman stain, 400x, shows blast cell (arrow) along with mature cells and normocytic normochromic red cells. Bone marrow (E) Leishman stain, 630x, shows heterogeneously sized blast cells with high nuclear cytoplasmic ratio, hyper chromatic nuclei, conspicuous nucleoli, and variable amount of basophilic agranular cytoplasm. Bone marrow flow cytometry dot plots (F) depict blasts (R1 red gate) with dim CD45 expression and low side scatter. 
$21 \%, \mathrm{E}=1 \%, \mathrm{M}=7 \%$ ), and platelet count of 77,000 cells/ $\mathrm{mm}^{3}$. The patient's aspartate aminotransferase level was 112 $\mathrm{U} / \mathrm{L}$, alanine aminotransferase was $123 \mathrm{U} / \mathrm{L}$, and alkaline phosphatase was $127.5 \mathrm{U} / \mathrm{L}$. Enzyme-linked immunosorbent assay for HIV infection was unreactive. Additional blood biochemical measures, renal function tests, blood sugar, electrolytes, and arterial blood gases were normal. Screening for vasculitis and connective tissue disorders was negative.

\section{Bone marrow biopsy}

Bone marrow examination, performed in view of atypical cells in the CSF, showed heterogeneous blast cells with high nucleocytoplasmic ratio, moderate fine chromatin, 1-2 nucleoli, and scant amount of cytoplasm, findings suggestive of acute lymphoblastic leukemia. Flow cytometry analysis was positive for CD10, CD19, CD20, CD38, and HLA-DR (figure, D-F).

\section{Diagnosis}

The patient was diagnosed with B-cell type acute lymphoblastic leukemia. The presence of leukemic blast cells in CSF confirmed the diagnosis of leukemic meningitis.

\section{Discussion}

Mature B-cell subtype of acute lymphoblastic leukemia frequently invades the CNS. In acute lymphoblastic leukemia, both CNS and peripheral nervous system are affected. CNS involvement is frequent in adults. Leptomeningeal infiltration of leukemic cells is seen in around 10\% of adult patients at diagnosis. Leptomeningeal metastasis is much more frequent at the time of relapse. A large series of adult patients with acute lymphoblastic leukemia experienced CNS involvement: $5 \%$ of cases $\left(77\right.$ of 1,508). ${ }^{6}$ CNS leukemia is characterized by the presence of leukemic blast cells or mononuclear cells in the CSF or cranial nerve palsies, or significant neurologic dysfunction. ${ }^{7}$ Leptomeningeal leukemic infiltration of basal meninges often presents with multiple cranial nerve palsies. ${ }^{8}$ Infrequent neurologic complications are cerebral infarcts and venous thrombosis, cerebral dysfunction after radiotherapy, and iatrogenic meningitis. CNS involvement may even be asymptomatic and becomes evident only after a CSF examination. ${ }^{9}$ A lumbar puncture should always be done in newly diagnosed acute lymphoblastic leukemia. In a patient with leptomeningeal infiltration, leukemic cells can be demonstrated in CSF with the help of cytology and flow cytometry. CSF analysis may reveal a variety of other meningitides like cryptococcal, tuberculous, viral, and acanthamoeba meningoencephalitis. MRI, in leukemia, may show intracranial and spinal meningeal enhancement, or a mass-like lesion. ${ }^{10} \mathrm{CNS}$ recurrence is a significant problem. The survival of untreated patients with leptomeningeal infiltration is limited to a few weeks. CSF examination is indispensable for evaluation of CNS involvement in acute lymphoblastic leukemia. The presence of blast cells in CSF or contamination of CSF by blast cell during traumatic lumbar puncture indicates a CNS relapse.

\section{Author contributions}

Dr. Ravindra: concept, drafting, revision, and analysis of manuscript. Dr. Rizvi: drafting, revision, and analysis of manuscript. Dr. Singh: concept, drafting, revision, and analysis of manuscript. Dr. Mayur: concept, drafting, and analysis of manuscript. Dr. Jain: drafting, revision, and analysis of manuscript. Dr. Uniyal: drafting, revision, and analysis of manuscript. Dr. Kumar: concept, revision, and analysis of manuscript.

\section{Study funding}

No targeted funding reported.

\section{Disclosure}

R. Garg receives regular honorarium for writing clinical summaries for Med Link Neurology, Med Link Corporation San Diego USA. I. Rizvi, H. Singh Malhotra, M. Mayur Mehta, M. Jain, M. Mati Goel, R. Uniyal, and N. Kumar report no disclosures relevant to the manuscript. Go to Neurology.org/N for full disclosures.

\section{References}

1. Garg RK, Malhotra HS, Gupta R. Spinal cord involvement in tuberculous meningitis. Spinal Cord 2015;53:649-657.

2. Mijajlovic M, Mirkovic M, Mihailovic-Vucinic V, Aleksic V, Covickovic-Sternic N. Neurosarcoidosis: two case reports with multiple cranial nerve involvement and review of the literature. Biomed Pap Med Fac Univ Palacky Olomouc Czech Repub 2014;158:662-667.

3. Adams HP Jr. Cerebral vasculitis. Handb Clin Neurol 2014;119:475-494.

4. Murthy H, Anasetti C, Ayala E. Diagnosis and management of leukemic and lymphomatous meningitis. Cancer Control 2017;24:33-41.

5. Keane JR. Multiple cranial nerve palsies: analysis of 979 cases. Arch Neurol 2005;62: 1714-1717.

6. Lazarus HM, Richards SM, Chopra R, et al. Central nervous system involvement in adult acute lymphoblastic leukemia at diagnosis: results from the international ALL trial MRC UKALL XII/ECOG E2993. Blood 2006;108:465-472.

7. Del Principe MI, Maurillo L, Buccisano F, et al. Central nervous system involvement in adult acute lymphoblastic leukemia: diagnostic tools, prophylaxis, and therapy. Mediterr J Hematol Infect Dis 2014;6:e2014075.

8. Mauermann ML. Neurologic complications of lymphoma, leukemia, and paraproteinemias. Continuum 2017;23:669-690.

9. Kuskonmaz B, Unal S, Gumruk F, Cetin M, Tuncer AM, Gurgey A. The neurologic complications in pediatric acute lymphoblastic leukemia patients excluding leukemic infiltration. Leuk Res 2006;30:537-541.

10. Guenette JP, Tirumani SH, Keraliya AR, Shinagare AB, Ramaiya NH, Jagannathan JP. MRI findings in patients with leukemia and positive CSF cytology: a single-institution 5-year experience. AJR Am J Roentgenol 2016;207:1278-1282. 


\section{Neurology}

\section{Clinical Reasoning: A patient with multiple cranial nerve palsies and areflexic paraparesis}

Ravindra Kumar Garg, Imran Rizvi, Hardeep Singh Malhotra, et al.

Neurology 2018;91;e392-e395

DOI 10.1212/WNL.0000000000005865

\section{This information is current as of July 23,2018}

\section{Updated Information \& Services}

References

Subspecialty Collections

\section{Permissions \& Licensing}

Reprints including high resolution figures, can be found at: http://n.neurology.org/content/91/4/e392.full

This article cites 10 articles, 1 of which you can access for free at: http://n.neurology.org/content/91/4/e392.full\#ref-list-1

This article, along with others on similar topics, appears in the following collection(s):

All Oncology

http://n.neurology.org/cgi/collection/all_oncology

Cerebrospinal Fluid

http://n.neurology.org/cgi/collection/cerebrospinal_fluid

Cranial neuropathy

http://n.neurology.org/cgi/collection/cranial_neuropathy

Ocular motility

http://n.neurology.org/cgi/collection/ocular_motility

Optic nerve

http://n.neurology.org/cgi/collection/optic_nerve

Information about reproducing this article in parts (figures,tables) or in its entirety can be found online at:

http://www.neurology.org/about/about_the_journal\#permissions

Information about ordering reprints can be found online:

http://n.neurology.org/subscribers/advertise

Neurology ${ }^{\circledR}$ is the official journal of the American Academy of Neurology. Published continuously since 1951, it is now a weekly with 48 issues per year. Copyright @ 2018 American Academy of Neurology. All rights reserved. Print ISSN: 0028-3878. Online ISSN: 1526-632X.

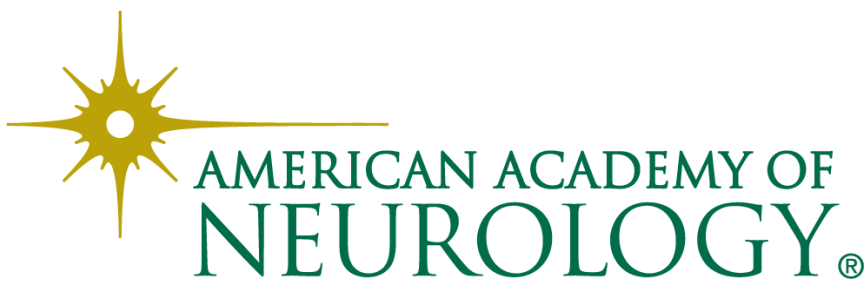

